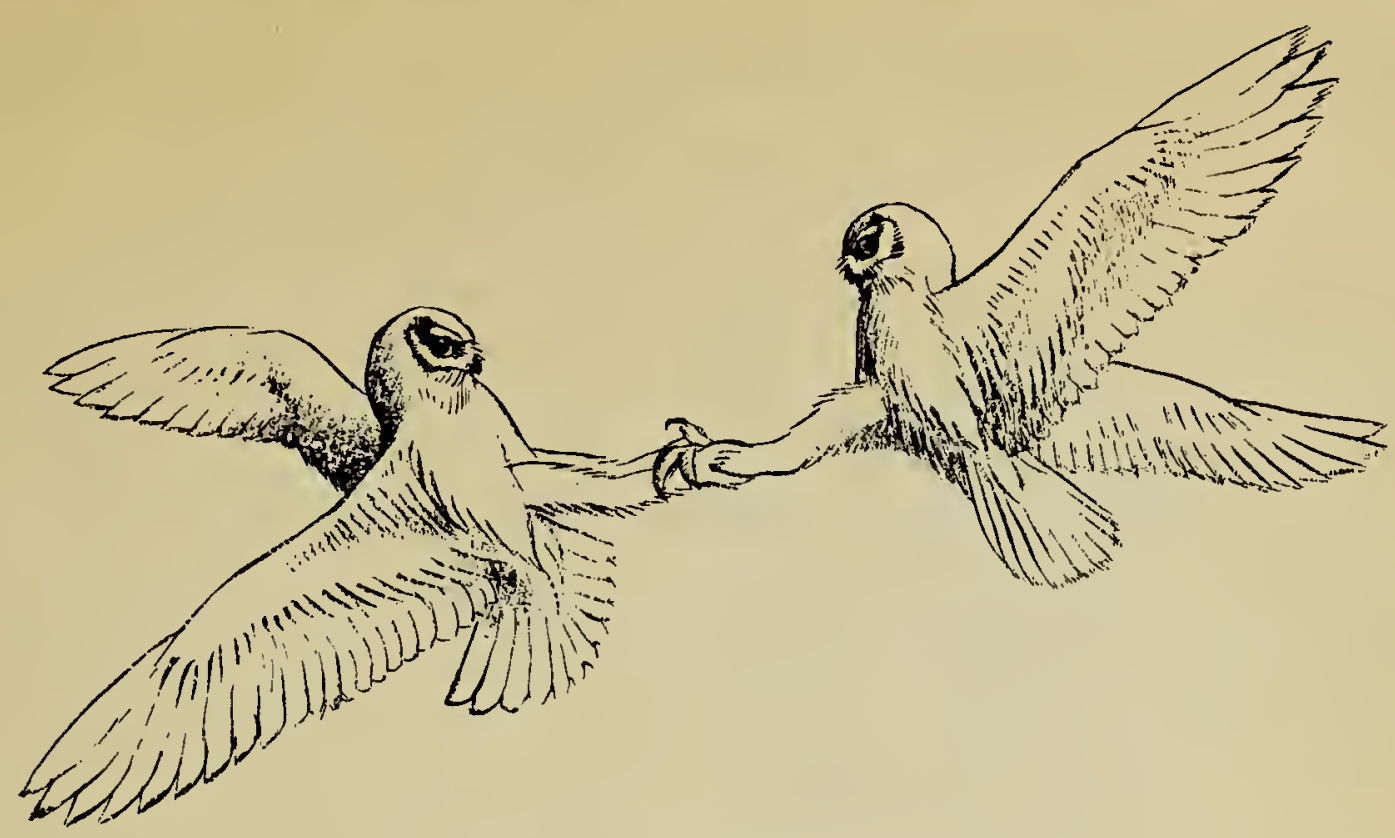

Short-eared Owl Behaviour.

Drawings by Ralph D. Carson

\title{
An Observation of Great Horned Owl Feeding Behaviour
}

by Rick Sanderson, Regina

As late as November 23, 1961, three species of owls were present within the Regina city limits. There was a Great Horned Owl (Bubo virginianus), a Short-eared Owl (Asio flammeus), and a Long-eared Owl (Asio otus). At present (January 14,1962 ), two owls may be seen, the Great Horned Owl and the Snowy Owl (Nyctea scandiaca).

After the blizzard on October 23, an unusual number of owls were seen in the city: there were as many as three Long-eared Owls (one of which was seen until November 25) and two Great Horned Owls (one of which is still in the area). I might add that on the day following the blizzard, October 24, Bill Fleming and I saw 21 Rough-legged Hawks flying over the Saskatchewan Museum of Natural History in twos and threes.

The Long-eared Owl was seen on very few occasions, but the Great Horned Owl remained in a stand of spruce trees on the eastern edge of the Waterfowl Park. Here it used a crow's nest as a feeding platform. On November 7, there were also two Short-eared Owls hunting in the marsh, bringing the number of owls hunting in an area of less than one square mile to four. After November 7 only one Short-ear was seen, and on November 26 the second Short- ear was found dead. However, a second pair of Short-ears was seen over a field near the marsh on December 2. (M. Belcher, L. Murray, R. Austin).

I collected a Great Horned Owl pellet on November 25 which contained bird feathers, bones and a talon. When the second Short-eared Owl was found dead the following day I noticed at once the similarity between its talons and the one taken from the pellet. They were a perfect match and I concluded that the Great Horned Owl had killed and eaten the first Short-eared Owl that disappeared after November 7. I examined the crow's nest and found several types of feathers. Some matched the primaries on the dead Short-ear, and most of the others resembled other feathers of the dead bird, particularly the breast feathers.

A factor which may have provoked the Great Horned Owl to attack the Short-ear, besides its natural aggressiveness, was possibly a shortage of food, as the area was undoubtedly heavily hunted by the four owls. There have been few instances when different species of owls have been known to attack each other and written reports concerning this aspect of their behaviour seem to be scarce. 